\title{
Ergänzende Materialien zu zwei VfZ-Beiträgen der Januar-Ausgabe
}

Neu bei den Zusatzangeboten: Ergänzende Materialien zu Sorin Radus Aufsatz „Der Aufbau des Sozialismus. Kaderschulen und Parteibürokratie in Rumänien die regionale Parteischule in Timişoara 1948 bis 1973“ im Januar-Heft 2021 der VfZ

Sorin Radu gibt in seinem Aufsatz einen tiefen Einblick in den Mikrokosmos der Kaderschulen in Rumänien zur Hochzeit des Kalten Kriegs, in denen die künftige Elite des kommunistischen Staats herangebildet werden sollte. Für Leserinnen und Leser, die des Rumänischen mächtig sind, stellen wir bei den Zusatzangeboten von VfZ-Online in der Rubrik „Beilagen“ Originalzitate aus Quellen und Forschungsliteratur zur Verfügung, die im Beitrag selbst ins Deutsche übersetzt wurden:

www.ifz-muenchen.de/vierteljahrshefte/zusatzangebote/beilagen/

Neu bei den Zusatzangeboten: Ergänzende Materialien zu René Schlotts Dokumentation „Ablehnung und Anerkennung. Raul Hilberg und das Institut für Zeitgeschichte“ im Januar-Heft 2021 der VfZ

Anhand bekannter und neu entdeckter Dokumente geht René Schlott der Frage nach, warum sich wissenschaftliche Mitarbeiterinnen beziehungsweise Mitarbeiter des Instituts für Zeitgeschichte wiederholt gegen eine Übersetzung von Raul Hilbergs Pionierstudie „The Destruction of the European Jews“ ins Deutsche aussprachen. Bei den Zusatzangeboten von VfZ-Online finden sich in der Rubrik „Beilagen“ Digitalisate der zehn Dokumente aus dem IfZ-Archiv und dem Verlagsarchiv S. Fischer, die René Schlott in seinem Beitrag präsentiert hat: www.ifz-muenchen.de/vierteljahrshefte/zusatzangebote/beilagen/ 